\title{
Understanding attitude of health care professional teachers toward interprofessional health care collaboration and education in a Southeast Asian
} country

This article was published in the following Dove Press journal: Journal of Multidisciplinary Healthcare

\section{Endang Lestari' \\ Renée E Stalmeijer ${ }^{2}$ Doni Widyandana ${ }^{3}$ \\ Albert Scherpbier ${ }^{2}$}

'Department of Medical Education, Medical and Health Allied Education Unit, Faculty of Medicine, Universitas Islam Sultan Agung, Semarang, Indonesia; ${ }^{2}$ Department of Educational Development and Research, School of Health Professions Education, Faculty of Health, Medicine and Life Sciences, Maastricht University, the Netherlands; ${ }^{3}$ Department of Medical Education, Faculty of Medicine, Gadjah Mada University, Yogyakarta, Indonesia
Correspondence: Endang Lestari Department of Medical Education, Medical and Health Allied Education Unit, Faculty of Medicine, Universitas Islam Sultan Agung, Jalan Raya Kaligawe KM 4, Semarang 50I I2, Indonesia

Tel +62 8II 290687 I

Email endanglestari@unissula.ac.id
Background: Faculty members play crucial roles as facilitators of learning for effective interprofessional education (IPE). However, faculty attitudes are reported to be barriers to successful implementation of IPE initiatives within health care education settings. This study aimed to investigate the following: 1) health care faculty members' attitudes toward interprofessional collaboration (IPC) and IPE; 2) factors affecting faculty members' perception toward IPC and IPE; and 3) health care professionals' perceptions toward factors that hamper the quality of IPC, and whether IPE is a possible remedy for the situation.

Methods: A survey was administered to medicine, nursing, midwifery, and dentistry faculty members at 17 institutions in Central Java Province, Indonesia. Respondents were asked to rate their attitudes toward IPC and IPE using a previously validated "Attitude toward Interprofessional Health care Collaboration and Education" scale. To help interpretation of the survey results, 4 monoprofessional focus groups (FGs) were conducted and 3 key participants who could not be present at the FG meetings were interviewed. We conducted a statistical analysis on the quantitative data and performed a thematic content analysis of the qualitative data using ATLAS Ti (version 7).

Results: The total response rate was $74.1 \%$. Nurses' mean scores for attitudes toward IPC and IPE were higher than those of other health care professionals. The main problems of IPC identified from the FG were as follows: 1) differing perceptions of the needs of patients among professionals; 2) unequal participation in decision-making; 3) lack of face-to-face interaction; and 4) overlapping of roles and responsibilities. Faculty members agreed that IPE has the potential to remedy these challenges as long as opportunities are provided to inculcate equal power and contribution in meeting patients' needs.

Conclusion: These findings indicate the necessity of convening faculty development programs regarding IPC and IPE. Additionally, innovative strategies must be developed for the implementation of IPC and IPE in a variety of academic settings.

Keywords: attitude of health care professionals, interprofessional education, interprofessional health care collaboration

\section{Introduction}

The complexity of current worldwide health care practices requires good interprofessional collaboration (IPC). Moreover, excessive attention to the issue of patient safety within health care practice - with the triple aim of better care for individuals, better health for populations, and lower health care costs - has stimulated substantial 
discussion on the value of the IPC-based approach to patient care. ${ }^{1}$ Health professionals from different professional backgrounds should work together as a team with patients and their families to improve patient outcomes, attain the highest quality of health care service, reduce costs, and improve the quality organizational outcomes. ${ }^{2}$

To address this challenge, the WHO in the Western Pacific Region, for instance, established the 5-year Human Resources for Health Action Framework (2011-2015), which stipulates that interprofessional education (IPE) is expected to play an important role in reducing the problems in the health care system by promoting effective collaboration., ${ }^{3,4}$ Therefore, it is suggested that IPE should become part of health care curricula worldwide. Health care professionals are advised to receive IPE to deliver patient-centered care as members of an interdisciplinary team, where students can learn IPC and bring their acquired knowledge, skills, and values into their practice in the future. ${ }^{4,5}$ IPE is defined as involving students of 2 or more professions engaged in learning with, from, and about each other to improve IPC and the quality of health care. ${ }^{6,7}$ IPE is understood to improve mutual respect and learners' understanding of other professions' roles and responsibilities. ${ }^{8}$ Implementation of IPE in the Asian context, including its effectiveness and challenges, has been previously reported. ${ }^{9-13}$

Faculty members or health care educators have crucial roles as facilitators of learning for effective IPE. ${ }^{14,15}$ In serving as effective teachers in IPE, they have to have good core competencies for interprofessional teaching, such as a commitment to IPE and practice, as well as positive role modeling. ${ }^{16}$ They also have to value the diversity and unique contributions of each health care profession within the health care team. ${ }^{16}$ However, there are different attitudes about IPC among different faculty members, such as a lack of respect for or knowledge of other members, which can become barriers to IPE. ${ }^{17}$ Previous research reported that faculty members who were trained in traditional monoprofessional systems did not stress the importance of IPC in delivering health care practice. ${ }^{18}$ Some programs, such as dentistry and medical programs, even emphasize the value of learners' self-reliance in delivering health care practice. ${ }^{18}$ Other complicating factors that might influence the implementation of IPE include the sociocultural situation, such as that in Southeast Asia, which is characterized by a very strong culture of social hierarchy. ${ }^{19}$ As a result, in the region, certain professionals such as doctors are considered to have the highest position in society, marginalizing other health care professionals such as dentists, nurses, and midwives. This significant hierarchical issue might further complicate effective IPC and could potentially influence the attitude of faculty members toward IPC. ${ }^{20,21}$

Previous studies have reported that attitudes toward other professionals and IPC affect the quality and performance of individuals engaged in teamwork. ${ }^{22,23}$ Considering this impact, the attitudes of professional health care educators should be explored as it might influence their performance in performing their duty as teachers in IPE programs. Previous studies reported on the attitudes of deans of health care education schools toward IPC and IPE in Asia. ${ }^{24,25}$ However, to the best of our knowledge, there have been limited publications that explore attitudes of faculty members toward IPC and IPE in the Asian context. A study in the Kingdom of Saudi Arabia reported favorable attitudes of health care faculty from 2 universities toward IPE. The current study aimed to answer the following research questions:

1. What are the attitudes of health professional teachers toward IPC and IPE in South East Asia?

2. Which factors influence health professional teachers' attitude toward IPC and IPE?

3. How do health professional teachers explain their perception toward IPC and IPE implementation?

\section{Methods}

\section{Research design}

To answer the research questions, we selected an explanatory, sequential mixed-methods design. ${ }^{26}$ We first collected quantitative data by administering a previously validated questionnaire, titled "Attitude Towards Interprofessional Health Care Collaboration and Education", to health care teachers. ${ }^{27}$ We specifically targeted teachers from the medical, nursing, midwifery, and dentistry programs of health care schools around Central Java Province, Indonesia. The results of the questionnaire were then used as input for the qualitative data collection, consisting of 4 monoprofessional FGs and interviews aimed to understand the underlying reasons of teachers' perceptions toward interprofessional health care collaboration and education, as well as to explore both the factors that hamper effective IPC and whether IPE could address the problem.

\section{Context}

Indonesia is a prototype of other densely populated East Asian countries with quite complex health problems. The primary health services are conducted at public health centers, which normally serve district areas. Primary health care is also done in private clinics or private practice. Meanwhile, the secondary 
and tertiary health care services are mostly provided in hospitals, either public or private. Interprofessional health services are generally carried out in both public health services and hospitals. Yet, health professionals such as dentists and medical doctors can perform independent services. Midwifes and nurses in Indonesia generally work collaboratively with other medical personnel, such as doctors and dentists, in both hospitals and public health centers. However, they sometimes run individual medical practices, especially in remote areas, where normally no doctors provide health care services. This might lead to conflicts among health professionals regarding overlapping of roles and responsibilities in private practice.

For educational institutions that offer only 1 study program, such as a midwifery academy or a college of nursing, IPE might be difficult to administer unless the program is conducted in collaboration with other universities that have multiple health-related study programs. The educational method of schools are not the same among the institutions; some use conventional teacher-centered approaches, with lecturing as the main teaching activity, and there are schools that have been implementing a horizontal-vertical integrated curriculum with hybrid problem-based learning (PBL).

Participants of this study were health professional teachers who worked in hospitals, public health care centers, or private health care practice. Teachers who work in hospitals and public health centers provide health care to patients and serve as clinical teachers for students of the clinical year programs. Working in hospitals and public health care centers is usually interprofessional in nature and thus requires IPC. However, working in private practice (quite common in Indonesia) is usually monoprofessional in nature. Some other teachers only perform their teaching role in the preclinical year program and do not run health care practice either independently or collaboratively in hospitals or clinics. This difference in the need to collaborate interprofessionally in their health care practice could influence teachers' perception toward IPC and IPE.

Regarding the implementation of IPE, there are very few universities in Indonesia that have actually incorporated an IPE program into their curriculum. Some of the universities have the intention to develop an IPE curriculum for their medical, nursing, midwifery, dentistry, and other healthallied programs. For this purpose, we conducted a survey of teachers' attitude toward IPC and IPE.

\section{Quantitative data collection: attitude questionnaire}

To evaluate health professionals' attitude toward interprofessional health care teams and IPE, Curran et $\mathrm{al}^{28}$ developed a detailed questionnaire, which consisted of 42 Likert-scaled items that were compiled and adopted from some previous studies. ${ }^{27} \mathrm{~A}$ set of questions referring to factors from the literature that we knew could influence teachers' attitudes toward implementation of new IPE program was added. These factors were as follows: 1) study program, ${ }^{28} 2$ ) educational background, 3) academic title, 4) institutions' background (whether the institution was under the Ministry of Health or Ministry of Higher Education), and 5) educational approach used in the school. ${ }^{29}$

All the Likert scales used a 5-point rating, where $1=$ strongly disagree and $5=$ strongly agree, with some reverse-scoring for negative questions. High scores on the questionnaire indicate good attitude toward IPC and IPE. The questionnaire was translated into the Indonesian language by means of a double/back-translation procedure to assess the consistency between the original and translated versions. The data were collected from 17 health professional schools around Central Java by the research team members. The research team visited the institutions and met the lecturers, mostly after a regular meeting of lecturers conducted by the schools. The team explained to the respondents the aim of the study and what the study was about. Some important terms such as IPE and interprofessional health care collaboration were also explained. It was explained to the faculty members that their participation was voluntary and would not affect their performance assessment and that the collected information would be kept confidential.

\section{Qualitative data collection: monoprofessional FG discussion (FGD) and semistructured interviews}

Four monoprofessional FGs were organized to explore the underlying reasons for faculty members' perceptions toward interprofessional health care collaboration and IPE. We deliberately chose not to conduct mixed-profession FGDs to overcome potential barriers to communicating openly and freely due to professional gaps and to encourage participants in the discussion. Besides, it was possible that mixedgroup FGDs may affect individual participants' responses, which can significantly have an effect on the outcome of studies. ${ }^{30}$ As the results of quantitative analysis indicated that education, academic title, institutions, and teaching approach influenced the perception toward the interprofessional health care team and IPE, these variables were considered for selecting participants. Each of the FG groups consisted of 6-12 lecturers. If any faculty member did not wish to take part in the FG, another member who met similar criteria 
was invited to participate. In addition, in-depth interviews were conducted with 3 senior lecturers of medical programs because they could not take part in the FGDs, and their perceptions were considered valuable. Lecturers majoring in medical education (Dian Apriliana Rachmawati [DAR]) and community medicine (Suryani Yulianti [SY]), who understood the concept and aims of this study, took part as facilitators of the FGDs. A discussion guide was used to facilitate each group discussion. The guide consisted of questions exploring health care professional teachers' perceptions regarding the following: 1) interprofessional health care collaboration and education, 2) problems of health care collaboration, and 3) the way in which IPE would contribute to remedying the problems. All FGDs and interviews were video-recorded.

\section{Analysis: attitude questionnaire}

Factor analysis was used to explore the construct validity of the Indonesian version of the questionnaire, and Cronbach's alpha was calculated to determine internal consistency using SPSS (version 20; IBM Corporation, Armonk, NY, USA). The Cronbach's alpha is acceptable if it is $>0.7$. The suitability of the correlation matrix was determined by the Kaiser-Meyer-Olkin (KMO) measure of sampling adequacy and Bartlett's test of sphericity. The KMO score is considered as good and applicable if it is $>0.7$ and the Barlett's test of sphericity is significant with $P<0.05$. The numbers of factors retained for the initial solutions and entered into the rotation were determined with the application of Kaiser's criterion (eigenvalues $>1$ ). The initial factor extraction was performed using principal component analysis. Finally, we performed an exploratory factor analysis using Promax rotation to define the clearer structure. We performed Kruskal-Wallis and Mann-Whitney $U$ statistical analyses using IBM SPSS (version 20.0) to evaluate the mean rank difference of total scores and dimension's score among subjects since the data were not normally distributed.

\section{Analysis: FGs and interviews}

All FGs and interviews were transcribed verbatim by medical education experts. The results of this exercise were summarized and sent to all the FGD participants and interviewees to do the member check procedure. ${ }^{31}$ The verbatim transcripts were made in Indonesian, and the contents were coded and analyzed by 2 medical education experts (author EL and DAR). The 2 researchers independently evaluated the transcripts and developed coding categories. Afterward, they met and discussed the coding categories and agreed on the coding, which they finally applied to the data. After this process, all members of the research team discussed the findings until they reached a consensus on the overarching themes. For the thematic content analysis of the qualitative data analysis, research software ATLAS.Ti (version 7; ATLAS.ti Scientific Software Development GmbH, Berlin, Germany) was used.

\section{Findings: factorial analysis}

The result of factorial analysis revealed that the KMO index was 0.953 , indicating sampling adequacy, while the value of Bartlett sphericity chi-square index was $12,657.129$, with $P<0.001$, rejecting the null hypothesis that the correlation matrix was an identity matrix and therefore unsuitable for factor analysis. Exploratory factor analysis with a limit of 4 extractions yielded 4 subscales. These results were different from those for the original questionnaire used by Curran et al; ${ }^{27}$ therefore, the authors had to rename the subscales. They were renamed as follows: subscale (1), attitude toward IPE and its implementation (22 items); subscale (2), attitude toward interprofessional health care practice (10 items); subscale (3), attitude toward negative views of interprofessional health care practice and education (5 items); and subscale (4), attitude toward negative views of campusbased IPE implementation (3 items), with Cronbach's alpha values of $0.95,0.88,0.72$, and 0.62 , respectively. Question number 10 ("Health professionals working as a team are more responsive than others to the emotional and financial needs of patients/clients") and Question number 41 ("Faculty should be rewarded for participation in interprofessional courses") were excluded from the questionnaire as both questions had low loading (Table 1). The final version of the questionnaire was named "Attitude toward Interprofessional Health Care Collaboration and Education (ATIHC\&E)".

\section{Quantitative results: questionnaire}

Of the 741 clinical and preclinical teachers from 17 institutions, 555 participants filled in the questionnaire; however, 6 of them were excluded because they did not complete the questionnaire. Thus, in total, data were collected from 549 participants, giving a response rate of 74.1\% (Table 2).

The Kruskal-Wallis and Mann-Whitney $U$ statistical analyses revealed that the median scores differed significantly among groups and characteristics (Table 3 ). The evaluated variables, namely, profession, level of education, academic title, length of employment, experience with working collaboratively in a health care team, institutions' background, and teaching method at school, were responsible for the score differences, and it can be inferred that these variables influenced teachers' attitudes toward IPC and IPE. Senior lecturers who had been working for $11-15$ years, had 
Table I Factor loading of each item

\begin{tabular}{|c|c|c|c|c|}
\hline & \multicolumn{4}{|l|}{ Loadings } \\
\hline & $\mathbf{I}$ & II & III & IV \\
\hline Subscales & $\alpha=0.951$ & $\alpha=0.833$ & $\alpha=0.717$ & $\alpha=0.617$ \\
\hline Attitude toward IPE and its implementation & & & & \\
\hline $\begin{array}{l}\text { Q15 Interprofessional learning will help students think positively about other health care } \\
\text { professionals }\end{array}$ & 0.451 & & & \\
\hline $\begin{array}{l}\text { QI7 Interprofessional learning before qualification will help health professional students to } \\
\text { become better team workers }\end{array}$ & 0.562 & & & \\
\hline $\begin{array}{l}\text { Q18 Patients would ultimately benefit if health care students worked together to solve } \\
\text { patients' problems }\end{array}$ & 0.473 & & & \\
\hline $\begin{array}{l}\text { Q19 Students in my professional group would benefit from working on small-group projects } \\
\text { with other health care students }\end{array}$ & 0.730 & & & \\
\hline Q20 Communication skills should be learned with integrated classes of health care students & 0.588 & & & \\
\hline Q2I Interprofessional learning will help to clarify the nature of patient problems for students & 0.722 & & & \\
\hline $\begin{array}{l}\text { Q23 Learning with students in other health professional schools helps undergraduates to } \\
\text { become more effective members of the health care team }\end{array}$ & 0.834 & & & \\
\hline $\begin{array}{l}\text { Q24 Interprofessional learning among health care students will increase their ability to } \\
\text { understand clinical problems }\end{array}$ & 0.712 & & & \\
\hline $\begin{array}{l}\text { Q25 Interprofessional learning will help students to understand their own professional } \\
\text { limitation }\end{array}$ & 0.723 & & & \\
\hline Q26 For small-group learning to work, students need to trust and respect each other & 0.429 & & & \\
\hline $\begin{array}{l}\text { Q27 Interprofessional learning among health professional students will help them to } \\
\text { communicate better with patients and other professionals }\end{array}$ & 0.778 & & & \\
\hline Q28 Team-working skills are essential for all health care students to learn & 0.422 & & & \\
\hline $\begin{array}{l}\text { Q29 Learning between health care students before qualification would improve working } \\
\text { relationships after qualification }\end{array}$ & 0.659 & & & \\
\hline Q30 Interprofessional learning utilizes resources better & 0.501 & & & \\
\hline $\begin{array}{l}\text { Q31 It is important for academic health center campuses to provide interprofessional } \\
\text { teaching opportunities }\end{array}$ & 0.713 & & & \\
\hline Q32 Interprofessional learning should be a goal of this campus & 0.746 & & & \\
\hline Q33 Students like courses taught by faculty from other academic departments & 0.684 & & & \\
\hline Q34 Students like courses that include students from other academic departments & 0.633 & & & \\
\hline Q35 Faculty should be encouraged to participate in interprofessional courses & 0.825 & & & \\
\hline Q36 Faculty like teaching to students in other academic departments & 0.573 & & & \\
\hline Q37 Faculty like teaching with faculty from other academic departments & 0.581 & & & \\
\hline Q39 Interprofessional efforts require support from campus administration & 0.641 & & & \\
\hline Attitude toward interprofessional health care & & & & \\
\hline $\begin{array}{l}\text { QI Patients/clients receiving interprofessional care are more likely than others to be treated } \\
\text { as a whole person }\end{array}$ & & 0.652 & & \\
\hline $\begin{array}{l}\text { Q3 The give and take among team members help them make better patient/client care } \\
\text { decisions }\end{array}$ & & 0.684 & & \\
\hline Q4 The interprofessional approach makes the delivery of care more efficient & & 0.643 & & \\
\hline $\begin{array}{l}\text { Q5 Developing patient/client care plan with other team members avoids errors in delivering } \\
\text { care }\end{array}$ & & 0.792 & & \\
\hline $\begin{array}{l}\text { Q7 Working in an interprofessional environment keeps most health professionals enthusiastic } \\
\text { and interested in their jobs }\end{array}$ & & 0.617 & & \\
\hline Q8 The interprofessional approach improves the quality of care to patients/clients & & 0.612 & & \\
\hline $\begin{array}{l}\text { QII The interprofessional approach permits health professionals to meet the needs of both } \\
\text { family caregivers and patients }\end{array}$ & & 0.630 & & \\
\hline $\begin{array}{l}\text { Q12 Having to report observations to a team helps team members better understand the } \\
\text { work of other health professionals }\end{array}$ & & 0.529 & & \\
\hline $\begin{array}{l}\text { QI3 Hospital patients who receive interprofessional team care are better prepared for } \\
\text { discharge than other patients }\end{array}$ & & 0.585 & & \\
\hline $\begin{array}{l}\text { Q14 The team meetings foster communication among members from different professions or } \\
\text { disciplines }\end{array}$ & & 0.468 & & \\
\hline $\begin{array}{l}\text { Attitude toward negative views of interprofessional health care practice and } \\
\text { education }\end{array}$ & & & & \\
\hline Q2 Developing an interprofessional patient/client care plan is excessively time consuminga & & & 0.544 & \\
\hline
\end{tabular}

(Contined) 
Table I (Continued)

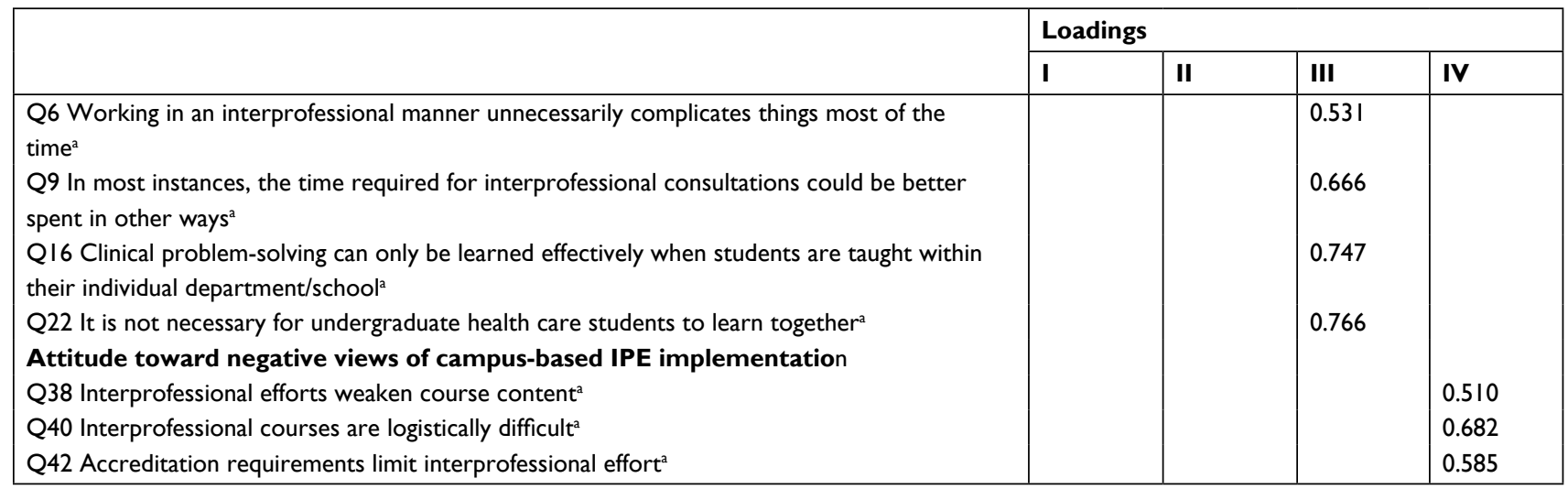

Notes: altems Q2, Q6, Q9, Q16, Q22, Q38, Q40, and Q42 are reverse-scored. $\alpha$ represents alpha Cronbach.

Abbreviation: IPE, interprofessional education.

Table 2 Demographic characteristics of respondents

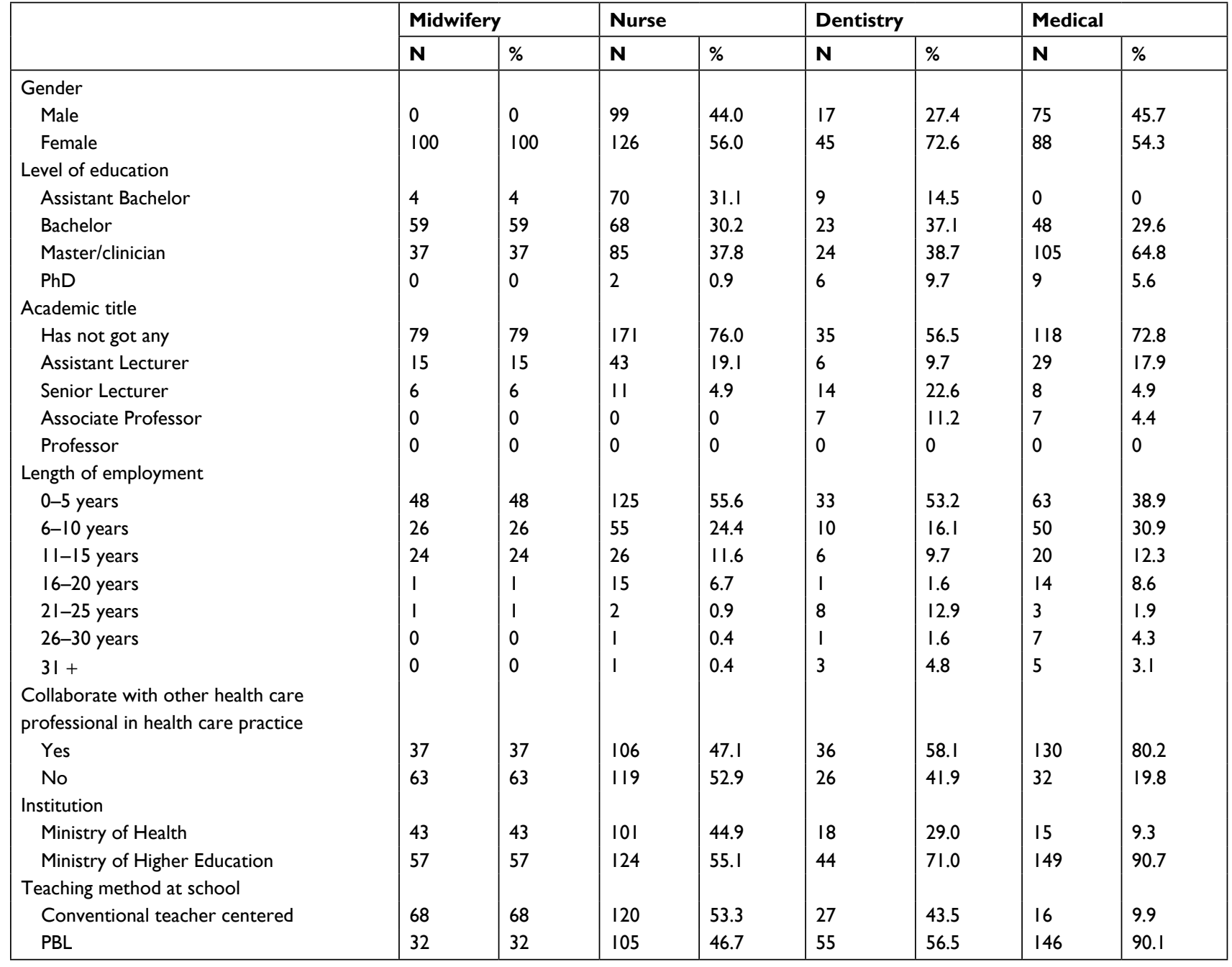

Abbreviation: PBL, problem-based learning. 
Table 3 Median and mean rank difference of the total ATIHC\&E score

\begin{tabular}{|c|c|c|}
\hline & \multicolumn{2}{|c|}{ Total ATIHC\&E score } \\
\hline & Median & $P$-value \\
\hline \multicolumn{3}{|l|}{ Profession } \\
\hline Midwife & 3.93 & $0.012^{\mathrm{a}}$ \\
\hline Nurse & 3.95 & \\
\hline Dentist & 3.92 & \\
\hline Medical doctor & 3.88 & \\
\hline \multicolumn{3}{|l|}{ Gender } \\
\hline Male & 3.88 & 0.132 \\
\hline Female & 3.93 & \\
\hline \multicolumn{3}{|l|}{ Level of education } \\
\hline Assistant Bachelor & 3.83 & $0.000^{\mathrm{a}}$ \\
\hline Bachelor & 3.88 & \\
\hline Master/clinician & 4.09 & \\
\hline $\mathrm{PhD}$ & 3.88 & \\
\hline \multicolumn{3}{|l|}{ Academic title } \\
\hline Has not got any & 3.91 & $0.00 \mathrm{I}^{\mathrm{a}}$ \\
\hline Assistant Lecturer & 4.00 & \\
\hline Senior Lecturer & 4.19 & \\
\hline Associate Professor & 3.79 & \\
\hline Professor & 0 & \\
\hline \multicolumn{3}{|l|}{ Length of employment } \\
\hline $0-5$ years & 3.90 & $0.000^{\mathrm{a}}$ \\
\hline $6-10$ years & 3.90 & \\
\hline $11-15$ years & 4.24 & \\
\hline $16-20$ years & 3.86 & \\
\hline $21-25$ years & 3.96 & \\
\hline $26-30$ years & 3.64 & \\
\hline $31+$ & 3.64 & \\
\hline \multicolumn{3}{|l|}{$\begin{array}{l}\text { Work collaboratively as health } \\
\text { care team }\end{array}$} \\
\hline No & 3.88 & $0.000^{b}$ \\
\hline Yes & 4.07 & \\
\hline \multicolumn{3}{|l|}{ Institution } \\
\hline Ministry of Health & 3.81 & $0.000^{\mathrm{b}}$ \\
\hline Ministry of Higher Education & 4.02 & \\
\hline \multicolumn{3}{|l|}{ Teaching method at school } \\
\hline Conventional teacher centered & 4.09 & $0.000^{b}$ \\
\hline $\mathrm{PBL}$ & 3.90 & \\
\hline
\end{tabular}

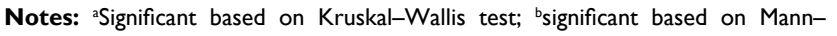
Whitney $U$ test.

Abbreviations: ATIHC\&E, Attitude toward Interprofessional Health Care Collaboration and Education; PBL, problem-based learning.

been working collaboratively in health care teams, and were from an institution under the ministry of Higher Education (which implements conventional teaching method) had higher median ATIHC\&E score. The median of the total ATIHC\&E score for nursing was the highest among the professionals, indicating that nurses had a more positive attitude toward IPE compared with other professionals. Clinicians have the highest median score among other educational levels. It is interesting that associate professors, those who had worked for $>30$ years, and those who worked in institutions applying PBL had the lowest median scores within their groups.

There was no significant difference in the mean scores for all items in the subscale "attitude toward the negative views of campus-based IPE implementation" among professions. Nevertheless, 5 items of the "attitude toward interprofessional health care" subscale and 1 item of the "attitude toward negative views of interprofessional health care practice and education" subscale had significantly different mean scores (Table 4).

\section{FGD and interview results}

To obtain the underlying reasons for teachers' attitudes toward health care IPC and IPE, the results of the questionnaires were discussed during FGDs and interviews with 29 participants from midwifery, nursing, dentistry, and medical programs (Table 5).

There were some challenges that could be identified from the FGDs concerning the implementation of IPE, which were as follows: 1) organization of the learning process, 2) reduction in students' opportunity to learn certain hands-on clinical skills due to collaboration, and 3) lack of good role model of collaboration in hospital. However, almost all of the participants in the FGDs were optimistic that 4) IPE could be a potential remedy for the problem of IPC.

1. Organization of the learning process

Some teachers stated that IPE would be difficult to apply within each programs' fixed schedule and curriculum. Besides, a health professional education curriculum is very time-intensive; therefore, it would be burdensome if the IPE would be added to an already full curriculum. The possible alternative solution suggested was that the IPE activities could be embedded within the learning activities of existing modules. Of course, this step requires the willingness of the module team to provide learning activities that use IPE, which requires collaborative work in designing the activities with health care teachers from other programs.

The burden in the preclinical year of medical students has been very high. Adding time for IPE will add to the burden on students. It will be additional work for teachers as we have to work together with teachers form other health care professional programs to arrange the learning activities.[...] [Medical teacher 3]

Some teachers also complained about logistic problems for IPE to be implemented. Problems of scheduling, class arrangement, and selection of tutors or instructors for the learning activities would certainly be very complicated. 
Table 4 Mean difference of each item

\begin{tabular}{|c|c|c|c|c|c|}
\hline Attitude toward IPE and its implementation & Midwifery & Nursing & Dentistry & Medical & P-Value \\
\hline $\begin{array}{l}\text { QI5 Interprofessional learning will help students think positively about } \\
\text { other health care professionals }\end{array}$ & $4.35 \pm 0.71$ & $4.40 \pm 0.66$ & $4.50 \pm 0.53$ & $4.20 \pm 0.64$ & 0.031 \\
\hline $\begin{array}{l}\text { Q17 Interprofessional learning before qualification will help health } \\
\text { professional students to become better team workers }\end{array}$ & $4.23 \pm 0.75$ & $4.29 \pm 0.61$ & $4.25 \pm 0.80$ & $4.06 \pm 0.86$ & 0.017 \\
\hline $\begin{array}{l}\text { QI8 Patients would ultimately benefit if health care students worked } \\
\text { together to solve patients' problems }\end{array}$ & $4.15 \pm 0.72$ & $4.26 \pm 0.68$ & $4.3 I \pm 0.58$ & $4.06 \pm 0.72$ & 0.027 \\
\hline $\begin{array}{l}\text { Q19 Students in my professional group would benefit from working on } \\
\text { small-group projects with other health care students }\end{array}$ & $4.19 \pm 0.82$ & $4.38 \pm 0.61$ & $4.18 \pm 0.75$ & $3.87 \pm 0.91$ & 0.000 \\
\hline $\begin{array}{l}\text { Q20 Communication skills should be learned with integrated classes of } \\
\text { health care students }\end{array}$ & $3.5 \mathrm{I} \pm 1.10$ & $4.03 \pm 0.8$ & $3.88 \pm 0.87$ & $3.73 \pm 0.91$ & 0.000 \\
\hline $\begin{array}{l}\text { Q2I Interprofessional learning will help to clarify the nature of patient } \\
\text { problems for students }\end{array}$ & $3.98 \pm 0.76$ & $4.24 \pm 0.63$ & $4.09 \pm 0.71$ & $3.73 \pm 0.95$ & 0.000 \\
\hline $\begin{array}{l}\text { Q23 Learning with students in other health professional schools helps } \\
\text { undergraduates to become more effective members of a health care team }\end{array}$ & $4.16 \pm 0.66$ & $4.35 \pm 0.56$ & $4.14 \pm 0.62$ & $4.00 \pm 0.81$ & 0.000 \\
\hline $\begin{array}{l}\text { Q24 Interprofessional learning among health care students will increase } \\
\text { their ability to understand clinical problems }\end{array}$ & $4.30 \pm 0.54$ & $4.26 \pm 0.6$ & $4.34 \pm 0.57$ & $4.09 \pm 0.7$ & 0.013 \\
\hline $\begin{array}{l}\text { Q25 Interprofessional learning will help students to understand their own } \\
\text { professional limitation }\end{array}$ & $4.12 \pm 0.6$ & $4.25 \pm 0.51$ & $4.05 \pm 0.77$ & $3.96 \pm 0.78$ & 0.000 \\
\hline $\begin{array}{l}\text { Q26 For small-group learning to work, students need to trust and respect } \\
\text { each other }\end{array}$ & $4.44 \pm 0.49$ & $4.44 \pm 0.62$ & $4.50 \pm 0.50$ & $4.30 \pm 0.59$ & 0.000 \\
\hline $\begin{array}{l}\text { Q27 Interprofessional learning among health professional students will } \\
\text { help them to communicate better with patients and other professionals }\end{array}$ & $4.32 \pm 0.66$ & $4.46 \pm 0.59$ & $4.29 \pm 0.49$ & $4.07 \pm 0.70$ & 0.000 \\
\hline Q28 Team-working skills are essential for all health care students to learn & $4.37 \pm 0.59$ & $4.43 \pm 0.58$ & $4.43 \pm 0.59$ & $4.22 \pm 0.61$ & 0.004 \\
\hline $\begin{array}{l}\text { Q29 Learning between health care students before qualification would } \\
\text { improve working relationships after qualification }\end{array}$ & $4.27 \pm 0.77$ & $4.39 \pm 0.57$ & $4.26 \pm 0.65$ & $4.04 \pm 0.72$ & 0.000 \\
\hline Q30 Interprofessional learning utilizes resources better & $4.47 \pm 0.61$ & $4.28 \pm 0.59$ & $4.32 \pm 0.56$ & $4.14 \pm 0.74$ & 0.001 \\
\hline $\begin{array}{l}\text { Q3I It is important for academic health center campuses to provide } \\
\text { interprofessional teaching opportunities }\end{array}$ & $4.23 \pm 0.60$ & $4.34 \pm 0.63$ & $4.32 \pm 0.50$ & $4.06 \pm 0.81$ & 0.001 \\
\hline Q32 Interprofessional learning should be a goal of this campus & $4.01 \pm 0.73$ & $4.09 \pm 0.6 \mathrm{I}$ & $3.79 \pm 0.85$ & $3.91 \pm 0.89$ & 0.014 \\
\hline $\begin{array}{l}\text { Q33 Students like courses taught by faculty from other academic } \\
\text { departments }\end{array}$ & $3.83 \pm 0.79$ & $4.02 \pm 0.68$ & $3.95 \pm 0.68$ & $3.80 \pm 0.77$ & 0.022 \\
\hline $\begin{array}{l}\text { Q34 Students like courses that include students from other academic } \\
\text { departments }\end{array}$ & $4.07 \pm 0.65$ & 4. $19 \pm 0.60$ & $4.02 \pm 0.61$ & $3.82 \pm 0.73$ & 0.000 \\
\hline $\begin{array}{l}\text { Q35 Faculty should be encourage to participate in interprofessional } \\
\text { courses }\end{array}$ & $4.28 \pm 0.62$ & $4.28 \pm 0.55$ & $4.29 \pm 0.55$ & $3.99 \pm 0.79$ & 0.000 \\
\hline Q36 Faculty like teaching to students in other academic departments & $3.59 \pm 0.92$ & $3.80 \pm 0.76$ & $3.74 \pm 0.74$ & $3.77 \pm 0.76$ & 0.166 \\
\hline Q37 Faculty like teaching with faculty from other academic departments & $3.72 \pm 0.87$ & $3.94 \pm 0.72$ & $3.82 \pm 0.71$ & $3.79 \pm 0.75$ & 0.056 \\
\hline Q39 Interprofessional efforts require support from campus administration & $4.16 \pm 0.70$ & $4.23 \pm 0.63$ & $4.19 \pm 0.59$ & $4.02 \pm 0.76$ & 0.019 \\
\hline \multicolumn{6}{|l|}{ Attitude toward interprofessional health care } \\
\hline $\begin{array}{l}\text { QI Patients/clients receiving interprofessional care are more likely than } \\
\text { others to be treated as a whole person }\end{array}$ & $4.50 \pm 0.50$ & $4.60 \pm 0.54$ & $4.47 \pm 0.56$ & $4.52 \pm 0.60$ & 0.186 \\
\hline $\begin{array}{l}\text { Q3 The give and take among team members help them make better } \\
\text { patient/client care decisions }\end{array}$ & $4.50 \pm 0.73$ & $4.39 \pm 0.75$ & $4.50 \pm 0.56$ & $4.38 \pm 0.73$ & 0.409 \\
\hline $\begin{array}{l}\text { Q4 The interprofessional approach makes the delivery of care more } \\
\text { efficient }\end{array}$ & $4.19 \pm 0.80$ & $4.27 \pm 0.65$ & $4.19 \pm 0.64$ & $4.07 \pm 0.83$ & 0.083 \\
\hline $\begin{array}{l}\text { Q5 Developing patient/client care plan with other team members avoids } \\
\text { errors in delivering care }\end{array}$ & $4.27 \pm 0.71$ & $4.34 \pm 0.60$ & $4.40 \pm 0.55$ & $4.28 \pm 0.68$ & 0.459 \\
\hline Q7 Working in an interprofessional environment keeps most health & $3.94 \pm 0.78$ & $4.22 \pm 0.58$ & $4.17 \pm 0.66$ & $4.08 \pm 0.74$ & 0.006 \\
\hline $\begin{array}{l}\text { Q8 The interprofessional approach improves the quality of care to } \\
\text { patients/clients }\end{array}$ & $4.38 \pm 0.61$ & $4.40 \pm 0.53$ & $4.37 \pm 0.52$ & $4.28 \pm 0.77$ & 0.260 \\
\hline $\begin{array}{l}\text { QII The interprofessional approach permits health professionals to meet } \\
\text { the needs of both family caregivers and patients }\end{array}$ & $3.59 \pm 0.90$ & $3.99 \pm 0.66$ & $3.85 \pm 0.76$ & $3.90 \pm 0.77$ & 0.000 \\
\hline $\begin{array}{l}\text { Q12 Having to report observations to a team helps team members better } \\
\text { understand the work of other health professionals }\end{array}$ & $4.07 \pm 0.71$ & $4.24 \pm 0.57$ & $4.27 \pm 0.51$ & $4.08 \pm 0.69$ & 0.016 \\
\hline $\begin{array}{l}\text { Q13 Hospital patients who receive interprofessional team care are better } \\
\text { prepared for discharge than other patients }\end{array}$ & $3.80 \pm 0.81$ & $4.29 \pm 0.67$ & $4.05 \pm 0.66$ & $3.99 \pm 0.76$ & 0.000 \\
\hline
\end{tabular}


Table 4 (Continued)

\begin{tabular}{|c|c|c|c|c|c|}
\hline Attitude toward IPE and its implementation & Midwifery & Nursing & Dentistry & Medical & P-Value \\
\hline $\begin{array}{l}\text { Q14 The team meetings foster communication among members from } \\
\text { different professions or disciplines }\end{array}$ & $4.31 \pm 0.63$ & $4.39 \pm 0.62$ & $4.45 \pm 0.53$ & $4.20 \pm 0.65$ & 0.031 \\
\hline \multicolumn{6}{|c|}{ Attitude toward negative views of interprofessional health care practice and education } \\
\hline $\begin{array}{l}\text { Q2 Developing an interprofessional patient/client care plan is excessively } \\
\text { time consuming }\end{array}$ & $3.00 \pm 1.08$ & $3.00 \pm 1.20$ & $3.04 \pm 1.07$ & $3.09 \pm 1.14$ & 0.869 \\
\hline $\begin{array}{l}\text { Q6 Working in an interprofessional manner unnecessarily complicates } \\
\text { things most of the time }\end{array}$ & $2.82 \pm 1.14$ & $3.08 \pm 1.10$ & $2.37 \pm 0.99$ & $2.77 \pm 1.18$ & 0.000 \\
\hline $\begin{array}{l}\text { Q9 In most instances, the time required for interprofessional } \\
\text { consultations could be better spent in other ways }{ }^{a}\end{array}$ & $3.32 \pm 1.08$ & $3.4 I \pm 1.19$ & $3.19 \pm 1.09$ & $3.33 \pm 1.04$ & 0.566 \\
\hline $\begin{array}{l}\text { Q16 Clinical problem-solving can only be learned effectively when } \\
\text { students are taught within their individual department/school }{ }^{a}\end{array}$ & $3.27 \pm 0.98$ & $3.10 \pm 1.22$ & $3.11 \pm 1.10$ & $3.36 \pm 1.00$ & 0.123 \\
\hline $\begin{array}{l}\text { Q22 It is not necessary for undergraduate health care students to learn } \\
\text { together }\end{array}$ & $3.38 \pm 1.07$ & $3.43 \pm 1.20$ & $3.56 \pm 1.06$ & $3.47 \pm 1.04$ & 0.766 \\
\hline \multicolumn{6}{|c|}{ Attitude toward negative views of campus-based IPE implementation } \\
\hline Q38 Interprofessional efforts weaken course content $\mathrm{t}^{\mathrm{a}}$ & $3.67 \pm 0.98$ & $3.40 \pm 0.99$ & $3.38 \pm 0.92$ & $3.39 \pm 0.96$ & 0.094 \\
\hline Q40 Interprofessional courses are logistically difficult ${ }^{a}$ & $3.12 \pm 1.10$ & $4.16 \pm 0.7 \mid$ & $4.20 \pm 0.62$ & $3.95 \pm 0.83$ & 0.133 \\
\hline Q42 Accreditation requirements limit interprofessional effort ${ }^{\mathrm{a}}$ & $3.54 \pm 0.93$ & $3.17 \pm 1.05$ & $3.24 \pm 1.06$ & $3.33 \pm 0.98$ & 0.210 \\
\hline
\end{tabular}

Notes: altems Q2, Q6, Q9, Q16, Q22, Q38, Q40, and Q42 are reverse-scored.

Abbreviation: IPE, interprofessional education,

Table 5 Demographic characteristics of FG and interview participants

\begin{tabular}{|c|c|c|c|c|c|c|c|c|}
\hline & \multicolumn{2}{|c|}{ Midwifery } & \multicolumn{2}{|c|}{ Nurse } & \multicolumn{2}{|c|}{ Dentistry } & \multicolumn{2}{|c|}{ Medical } \\
\hline & $\mathbf{N}$ & $\%$ & $\mathbf{N}$ & $\%$ & $\mathbf{N}$ & $\%$ & $\mathbf{N}$ & $\%$ \\
\hline \multicolumn{9}{|l|}{ Gender } \\
\hline Male & 0 & 0 & 3 & 50.0 & 3 & 50.0 & 3 & 30.0 \\
\hline Female & 7 & 100 & 3 & 50.0 & 3 & 50.0 & 7 & 70.0 \\
\hline \multicolumn{9}{|l|}{ Age, years } \\
\hline $20-30$ & 3 & 42.9 & 2 & 33.3 & 2 & 33.3 & 4 & 40.0 \\
\hline $31-40$ & I & 14.3 & 4 & 66.7 & I & 16.7 & 3 & 30.0 \\
\hline $4 I-50$ & 3 & 42.9 & 0 & 0 & 2 & 33.3 & 0 & 0 \\
\hline 51 and more & 0 & 0 & 0 & 0 & I & 16.7 & 3 & 30.0 \\
\hline \multicolumn{9}{|l|}{ Level of education } \\
\hline Bachelor & 0 & 0 & 0 & 0 & I & 16.7 & 5 & 50.0 \\
\hline Master/clinician & 7 & 100 & 6 & 100 & 5 & 83.3 & 2 & 20.0 \\
\hline $\mathrm{PhD}$ & 0 & 0 & 0 & 0 & 0 & 0 & 3 & 30.0 \\
\hline \multicolumn{9}{|l|}{ Academic title } \\
\hline Has not got any & 4 & 57.1 & I & 16.7 & 3 & 50 & 7 & 70.0 \\
\hline Assistant Lecturer & 2 & 28.6 & 5 & 83.3 & 2 & 33.3 & 2 & 20.0 \\
\hline Senior Lecturer & I & 14.3 & 0 & 0 & 0 & 0 & 2 & 20.0 \\
\hline Associate Professor & 0 & 0 & 0 & 0 & I & 16.7 & I & 10.0 \\
\hline Professor & 0 & 0 & 0 & 0 & 0 & 0 & 0 & 0 \\
\hline \multicolumn{9}{|l|}{ Length of employment } \\
\hline $1-15$ years & 4 & 57.1 & 6 & 100 & 5 & 83.0 & 8 & 80.0 \\
\hline$>15$ years & 3 & 28.6 & 0 & 0 & I & 7.0 & 2 & 20.0 \\
\hline \multicolumn{9}{|l|}{ Involved/runs health care practice } \\
\hline Yes & 3 & 42.9 & 4 & 66.7 & 5 & 83.3 & 9 & 90.0 \\
\hline No & 4 & 57.1 & 2 & 33.3 & I & 16.7 & I & 10.0 \\
\hline \multirow{2}{*}{\multicolumn{9}{|c|}{$\begin{array}{l}\text { Collaboration with other health care } \\
\text { professionals in health care practice }\end{array}$}} \\
\hline & & & & & & & & \\
\hline Yes & 3 & 42.9 & 4 & 66.7 & 5 & 83.3 & 4 & 40.0 \\
\hline No & 0 & 0 & 0 & 0 & 0 & 0 & 5 & 50.0 \\
\hline Is not involved in health care practice & 4 & 57.1 & 2 & 33.3 & I & 16.7 & I & 10.0 \\
\hline
\end{tabular}

Abbreviation: FG, focus group. 
In my opinion, before IPE is implemented, we must be prepared for logistic problems. We will need a lot of discussion rooms and clinical skill rooms with all equipment needed for the skill teaching. Are we ready for this? [Nursing teacher 4]

The problem of organizing the learning was also voiced by teachers from educational institutions that only provided a single health care professional education program. It is common in Indonesia for schools to administer a single professional education program, such as a school of midwifery. Normally, these schools are under the organization of Ministry of Health. This monoprofessional learning situation makes it difficult for them to run IPE, unless they collaborate with other institutions that organize different health care professional education programs.

We have difficulty implementing IPE because we only manage 1 midwifery program [...] [Midwifery teacher 2]

2. IPE might reduce students' opportunity to learn hands-on clinical skills

Some teachers were not supportive of IPE because they felt that by learning to handle patients together, students would lose opportunities to practice clinical skills that they should also master but would eventually become (in clinical practice) the role and responsibility of students from other professions. They would have more opportunities to learn the skills when studying in a monoprofessional setting.

[...] For example, medical students must also be able to master administering infusion; when there are no other professional students working together with them, they will certainly be challenged to master these skills. In contrast, if there are nursing students learning together with medical students in an IPE context, infusion will be done by nursing rather than by medical students as the treatment is within the nurse's responsibility. [Medical teacher 5]

3. Lack of good role models of health care team collaboration in hospitals

Some teachers mentioned concerns that actual IPC in health care is problematic. Participants talked about problems such as the different perceptions of the needs of patients between or among professionals, unequal participation in decision-making, lack of face-to-face interaction, and overlapping of roles and responsibilities. Observing this could affect students' perceptions about and eventual performance of IPC. The teachers argued that in order for IPE to run properly, hospitals must be prepared to improve the quality of the collaboration culture among their health care professionals.
Collaboration between health workers in the hospital still needs to be improved, as students will learn to perform good team collaboration from the workers. [Nursing teachers 2]

The main challenges of interprofessional health care collaboration that could be identified from the FGDs and the interviews were A) the differing perceptions of the needs of patients between or among professionals, B) unequal participation in decision-making, C) lack of face-to-face interaction, and D) overlapping of roles and responsibilities.

A. Differing perception of the needs of patients between or among professionals

Some teachers explained that the core issues that cause conflict within interprofessional health care teams were differences in perception regarding the treatment or the patient's needs. As they have different academic backgrounds and knowledge, the offered patient management is sometimes different, which in turn has the potential to lead to a conflict between or among health professionals.

Sometimes, I had different perception with the doctor concerning the appropriate time to discharge a patient as the result of differing reasoning between us. [Nursing teacher 5]

B. Unequal participation in decision-making

Health professionals, such as nurses and midwives, reported that they often find obstacles in participating in decision-making, especially during ward rounds. They only served to convey information and answer doctors' questions regarding the condition of the patients, and not be involved in providing input to decision-making. From the FG discussion, the main cause of unequal participation could be identified from the history of health care professional education, which was considered as unequal. The long-standing habits became a challenge for developing a collaboration culture in hospitals:

\section{[...] However, in my opinion, it (the unequal participation)} cannot be separated from history. The nurse's education was high school level in the colonial era; meanwhile, medical education was a higher education program since its establishment.[...] Nurses have been considered doctors' assistants in hierarchy. [Nursing teacher 6]

C. The lack of face-to-face interaction

Unpleasant communication among health professionals was a complaint among almost all professionals in the discussion. However, all participants understood that health professionals are busy, and that therefore face-to- 
face communication is difficult to conduct; consequently, documentation becomes a vital tool for communication.

In dealing with a patient's problem, communication is done through medical records, so, there is no face-to-face communication done. This may result in suggestions given by other professionals being unclear and misunderstood [...]. [Midwifery teacher 4]

D. Overlapping of roles and responsibilities

Participants in FGs argued that overlapping roles and responsibilities were important problems in interprofessional health care collaboration. A lack of clarity over roles and responsibilities of professionals can lead to a breakdown in communication, which may have a direct impact on the patients and their outcomes.

From the discussion, it could be identified that overlapping roles among health care professionals, community or client misperception concerning health care service, health care practice regulation not being put into effect, and economic factors or professional income problem, were the main triggers.

Sometimes, people do not know what illness they had and to what health professionals they have to visit to heal their sickness. [Midwifery teacher 1]

4. IPE has the potential to remedy the problem. Most teachers argued that IPE provided an opportunity to students to improve the skills needed for better IPC, such as communication and team-working skills, as well as to respect the roles and responsibilities of other professions. They also suggested that IPE requires integration early in undergraduate curricula. Some methods of the learning activities were also identified during the FGDs. The point was that the activities should provide opportunity to share knowledge and skill, as well to inculcate equal power and contribution in solving patients' problems based on each professional's roles and responsibilities.

In my opinion, to inculcate understanding of role and responsibility and of good and equal participation of health care professionals, I suggest that IPE should include discussion forums. Students should be trained to conduct discussions among different health care professionals with topics around the management of patients. [Medical teacher]

Some teachers also suggested that the use of technology could be applied to reduce the logistical complexities. Technology such as a virtual tutorial could be applied in learning situations.

\section{Discussion}

This present study explored the attitude of health care professionals toward IPC and IPE, what are the most important factors influencing the attitude, how the teachers explain factors that mitigate health care collaboration practice in Indonesia, and whether IPE could remedy the problems. To answer the first and second questions, we had the original survey titled "Attitude toward Interprofessional Care and Education" by Curran et $\mathrm{al}^{27}$ translated into Indonesian and adapted to the Indonesian context. The translated version proved valid and reliable after an exploratory factor analysis resulting in 40 items.

Professional background, educational background, academic title, length of employment, working collaboratively as health care team, institutional background, and the teaching approach used in the school appear to be characteristics that were associated with the attitudes of health professionals toward IPC and IPE. Qualitative data analysis showed that health professional education teachers had negative perceptions toward health care collaboration in hospitals. They had positive perceptions toward IPE implementation, however, despite their complaint concerning the challenges that would be faced during the IPE implementation.

The findings indicated that nurses had a better attitude toward IPC and IPE than other health professionals. This finding confirms the results of a previous study, ${ }^{27}$ which reported that medical faculty members had significantly lower mean score than nursing faculty on attitude toward IPE. Nursing faculty members were also reported to have a more favorable attitude than any other profession in another study. ${ }^{32}$ The positive attitude of the nurses toward interprofessional health care teams and IPE may be due to the nature of the profession, which requires constant cooperation with other professionals during performance of their duties. The positive attitude of nurses toward health care teams and IPE may also be due to the higher expectation of the nursing profession to achieve better results from IPE to improve the quality of collaboration among health care teams. Meanwhile, the characteristics of medical, dentistry, and midwifery education, which emphasizes the importance of independence and confidence in delivering care practice, might influence the professionals' lower attitude toward IPC and IPE. ${ }^{15}$ As faculties have a very critical role in delivering IPE, the findings suggested that conducting faculty development programs is essential to prepare and support IPE facilitators in order to deliver effective IPE. ${ }^{2}$

The survey results suggested that health professional teachers' backgrounds were associated with the attitudes 
toward IPC and IPE. The findings confirmed previous research that reported that health professionals experienced in IPC in health care teams had a more positive perception of IPE and valued teamwork. ${ }^{23}$ Health professional teachers from institutions with a PBL approach had low score regarding attitude toward health care practice and IPE. Previous literature has reported that faculties of institutions with a fixed curriculum, such as the ones applying the PBL approach, tend to be reluctant to implement new programs such as IPE because there will be some logistic problems that should be addressed, such as curriculum, timetable, class size, and assessment methods. ${ }^{33-35}$ In the PBL curriculum, timetables are fixed, which makes it difficult to embed learning activities such as IPE.

Our analysis of the qualitative data indicates that the faculty's perceptions of IPE is positive, as they believe that IPE has the potential to remedy the problem of interprofessional health care collaboration, consistent with the results from other studies exploring this area. ${ }^{36-38}$ These studies suggested that positive perceptions of IPE are global and held in common by health professional teachers. ${ }^{39}$ However, this study indicated that there were some teachers who worried about the barriers that will be encountered on implementing IPE.

It was reported in the literature that implementation of an interprofessional curriculum is challenging. ${ }^{33,34}$ Some challenges that hinder the development of IPE include inflexible curricula, timetables, established separate clinical placement systems, large student numbers, institutional policies, and professional accreditation requirements, also reported in other studies elsewhere. ${ }^{33,34}$ Many of these barriers were also identified in our FGDs and interviews as being hurdles that had to be overcome. However, most teachers believed that with strong commitment to IPE and the intention to remedy IPC problems, the barriers could be overcome. In this context, executive leadership commitment to IPE is critical. This commitment needs to be in the form of role models for change, authority to challenge resistance, and to establish and lead IPE accountability. ${ }^{40}$

The positive perception toward IPE was demonstrated by the enthusiastic suggestions regarding where and how IPE could be used to improve teaching and learning in the health professional education. Possible topics, materials, and methods of teaching and learning were suggested. Participants suggested that the learning activities should include discussion, as well as sharing of knowledge and skills to support equal contributions to solve patients' problem among health care professional students. Previous studies reported that some active learning approaches, such as community-based learning, ethics, communication, discussion, epidemiology, evidence-based practice, project-based learning, and role-play simulations, were effective topics for IPE..$^{35,40,41}$

It was interesting that some teachers enthusiastically suggested the use of new technologies to develop IPE collaboration. Due to logistical complexities, such as timetabling and a large number of students, technologies such as interprofessional virtual tutorials and virtual simulation technology could facilitate improvement of collaboration. Recent research in this area is promising. ${ }^{42}$

Moreover, teachers agreed that IPE requires early integration in undergraduate curricula. They recommended embedding IPE within some modules offered in the curriculum of the health profession education programs. The suggestion to embed IPE early as an integrative componentrather than as an optional supplement - to the core curriculum is gaining support. ${ }^{43}$ It was reported that early exposure to teams from at least 3 disciplines will increase collaboration and develop mutual recognition and respect. ${ }^{44}$

Some challenges on interprofessional health care collaboration could be identified during the FGDs. One of the participants revealed that the differences in perception about the patient's condition often led to goal differences, which in turn led to conflicts between health workers. ${ }^{45}$ A conflict resolution strategy that focuses on developing conflict resolution protocols and a reliance on the leadership of the organization should be developed by the health care team members and should be implemented to minimize the challenges of these conflicts. ${ }^{46}$ Learning how to do this is a vital part of IPE outcomes. ${ }^{47}$

Another reported problem of interprofessional health professional collaboration was unequal participation in decision-making, which indicates unequal power relations among health professionals. Similar problems were reported in other research. ${ }^{20,45,46}$ This historical subordinate relationship may contribute to behaviors that are not conducive to collaboration. ${ }^{48,49}$ The uneven knowledge acquisition made the doctors settle on their own decisions and disregard nurses and health professionals other than doctors, as opposed to accepting unsolicited information. ${ }^{46}$ The perception that other health professionals would be inferior to doctors also gives nurses and midwives less confidence to take active participation in solving patients' problems. It has been frequently reported that nursing students were perceived inferior to medical students with respect to several characteristics, including status in society, competence, and academic ability. ${ }^{9,11,50}$ IPE - with 
its various learning activities - must facilitate students to develop confidence. Nursing, midwifery, and other health professional students should take their profession forward and collaborate with others, to the ultimate benefit of all concerned. They should recognize that each health profession is different from, but equally as important as, medicine for people's health. They have to be confident of the value of their own profession and therefore of the legitimacy of their roles as full members (and sometimes leaders) of health care teams and can therefore identify and pursue their roles in their own context. IPE carried out through the education of health professional education, is expected to overcome the self-distrust problem. ${ }^{18}$

Dialogue through documentation is another problem that could lead to conflict in interprofessional health care. Faceto-face communication is understood as an important facet of interprofessional health care, although in certain situations, such as in an acute hospital setting, case notes are often the main source of communication when professionals cannot hold regular interprofessional meetings. However, there should be more direct interaction between members of the interprofessional team because they may occasionally have misperceptions when communication is only done through documentation. ${ }^{45}$ To resolve this issue, integration through communication activities, such as multidisciplinary rounds within each team, weekly meetings of clinical case managers, and medical staff meeting reports, could be performed. ${ }^{51}$ Health professionals in hospitals should become role models to implement good IPC in health care services and create a culture of collaboration and communication within the health care team.

This study contributes to literature as, to the best of our knowledge, it is the only study that has explored the attitude of health care professionals toward IPC and IPE by applying a mixed-method study approach, which allows exploring in-depth information of health care professionals' perception toward IPC and IPE. Previous studies on similar topics generally used a quantitative design. Although the data were collected from 17 health care educational institutions in Central Java Province, they might not represent the perceptions of all Indonesian health care professionals. Similar studies could be conducted with a broader population.

\section{Conclusion}

Nurses' mean scores for the attitude toward health care practice and IPE were higher than those of other health care professionals. The findings have implications both for the advancement of IPE within academic institutions and for collaborative strategies to promote faculty development initiatives. Faculty members agreed that IPE has the potential to remedy health care collaboration problems as long as it provides opportunity to inculcate equal power and contribution in solving patients' problems. There were 4 main problems of interprofessional health care collaboration that could be identified from the FGDs and interviews. Communication and conflict resolution skills are urgent subjects that need to be taught in IPE, because these mentioned problems potentially generated conflict. Health professionals in hospitals or other health care services should become role models to help create and implement good IPC in health care services and ensure successful implementation of IPE initiatives. Meanwhile, hospitals and other health care services should also help and ensure that various programs create a good, positive culture of IPC, so that patients can be treated effectively.

\section{Ethics approval and consent to participate}

The study was approved by the Bioethics Committee for Medical/Health Research Faculty of Medicine, Islamic University of Sultan Agung Semarang (letter number 290/ XII/2013/Komisi Bioetik) and was conducted at 17 health professional schools in Central Java, Indonesia. Participants would not be exposed to physical risk for taking part this study. Information regarding the purpose of the study was explained to the respondents by the research team members, the academic administrators of the school, or representatives appointed by the academic administrators. The respondents were informed that their participation in this study was on a voluntary basis and that their answers to the items would not affect any consideration on teacher performance assessment. Consent was implied by the fact that respondents completed the questionnaire and took part in the FGD voluntarily. To ensure confidentiality, we anonymized both the questionnaires and the transcripts of the FGDs and personal interviews.

\section{Data sharing statement}

Materials and supporting data are available for download on the following website: https://drive.google.com/drive/ folders/0B CPaqF-zFD3cHBVZWtaaT13STQ? usp=shar ing. All files may be used for research and education without further consent. 


\section{Acknowledgments}

The authors wish to thank the Directorate General of Higher Education, Ministry of Research, Technology and Higher Education, Republic of Indonesia, for funding the project; all teachers and health care professionals who participated in the study; and Dian Apriliana Rachmawati, Suryani Yulianti, Ika Rosdiana, and Endang Surani (ES), who are research associates in the Medical and Health Allied Education Unit of the Faculty of Medicine, Universitas Islam Sultan Agung, for their assistance in conducting the study. The project was funded by the Directorate General of Higher Education, Ministry of Research, Technology and Higher Education, Republic of Indonesia, under the scheme "Penelitian Produk Terapan". The authors alone are responsible for the writing and content of this paper.

\section{Author contributions}

EL designed and performed the studies, analyzed the data, and drafted the manuscript. RES, DW, and AS contributed to the study's conception and helped draft the manuscript. All authors contributed toward data analysis, drafting and revising the paper and agree to be accountable for all aspects of the work.

\section{Disclosure}

The authors report no conflicts of interest in this work.

\section{References}

1. Addy C, Browne T, Blake E, Bailey J. Enhancing interprofessional education: integrating public health and social work perspectives. $\mathrm{Am}$ J Public Health. 2015;105(Suppl 1):S106-109.

2. Reeves S, Fletcher S, Barr H, et al. A BEME systematic review of the effects of interprofessional education: BEME Guide No. 39. Med Teach. 2016;38(7):656-668.

3. WHO. WPRO Human Resources for Health Action Framework for the Western Pacific Region (2011-2015). Manila: WHO Regional Office for the Western Pacific; 2012.

4. WHO. Transforming and Scaling up Health Professionals'Education and Training. World Health Organization Guidelines. Switzerland: World Health Organization; 2013.

5. Frenk J, Chen L, Bhutta ZA, et al. Health professionals for a new century: transforming education to strengthen health systems in an interdependent world. Lancet. 2010;376(9756):1923-1958.

6. Barr H. Interprofessional education: the fourth focus. J Interprof Care. 2007;21(Suppl 2):40-50.

7. D'Amour D, Oandasan I. Interprofessionality as the field of interprofessional practice and interprofessional education: an emerging concept. J Interprof Care. 2005;19(Suppl 1):8-20.

8. Foster R, Macleod Clark J. Moderating the stereotypical views of health and social care students: the role of interprofessional education. J Interprof Care. 2015;29(1):34-40.

9. Lestari E, Stalmeijer R, Widyandana D, Scherpbier A. Understanding students' readiness for interprofessional learning in an Asian context: a mixed-methods study BMC Medical Education. 2016;16(179):1-11.

10. Chua AZ, Lo DY, Ho WH, et al. The effectiveness of a shared conference experience in improving undergraduate medical and nursing students' attitudes towards inter-professional education in an Asian country: a before and after study. BMC Med Educ. 2015;15(1):1-7.
11. Lestari E, Yuliyanti S, Rosdiana I, Surani E, Luailiyah A. Contributing Factors of Acceptance and Rejection to Interprofessional Education: Undergraduate Students' Perception. Online J Health Allied Sci. 2017;6(1):1-9.

12. Al-Qahtani MF. Measuring healthcare students' attitudes toward interprofessional education. J Taibah Univ Med Sci. 2016;11(6):579-585.

13. Hegde S, Gajre MP, Shah H, Soares NS. Interprofessional education and practice in an Indian setting. J Taibah Univ Med Sci. 2017;12(3): 265-267.

14. Cleghorn GD, Baker GR. What faculty need to learn about improvement and how to teach it to others. $J$ Interprof Care. 2000;14(2):147-159.

15. Parsell G, Bligh J. The development of a questionnaire to assess the readiness of health care students for interprofessional learning (RIPLS). Med Educ. 1999;33(2):95-100.

16. Freeth D, Reeves S, Koppel I, Hammick M, Barr H. Evaluating Interprofessional Education: A Self-Help Guide. Higher Education Academy Health Sciences and Practice Network. London; 2005.

17. Steinert Y. Learning together to teach together: interprofessional education and faculty development. J Interprof Care. 2005;19(Suppl 1):60-75.

18. Oandasan I, Reeves S. Key elements of interprofessional education. Part 2: factors, processes and outcomes. J Interprof Care. 2005;19(Suppl 1): $39-48$.

19. Houben V. Sociocultures of Insular Southeast Asia: between History, Area and Social Studies. Transcience. 2014;5(1):28-35.

20. Clarin OA. Strategies to Overcome Barriers to Effective Nurse Practitioner and Physician Collaboration. J Nurse Practitioners. 2007;3(8):538-548.

21. Hall P. Interprofessional teamwork: professional cultures as barriers. J Interprof Care. 2005;19(Suppl 1):188-196.

22. Heinemann GD, Schmitt MH, Farrell MP, Brallier SA. Development of an attitudes toward health care teams scale. Eval Health Prof. 1999;22(1):123-142.

23. Thannhauser J, Russell-Mayhew S, Scott C. Measures of interprofessional education and collaboration. $J$ Interprof Care. 2010;24(4):336-349.

24. Lee B, Celletti F, Makino T, Matsui H, Watanabe H. Attitudes of medical school deans toward interprofessional education in Western Pacific Region countries. J Interprof Care. 2012;26(6):479-483.

25. Makino T, Nozaki S, Lee B, et al. Attitudes of nursing school deans toward interprofessional education in Western Pacific Region countries. $J$ Interprof Care. 2015;29(5):518-519.

26. Johnson RB, Onwuegbuzie AJ. Mixed Methods Research: A Research Paradigm Whose Time Has Come. Educ Res. 2004;33(7):14-26.

27. Curran VR, Sharpe D, Forristall J. Attitudes of health sciences faculty members towards interprofessional teamwork and education. Med Educ. 2007;41(9):892-896.

28. Michalec B, Giordano C, Arenson C, Antony R, Rose M. Dissecting firstyear students' perceptions of health profession groups: potential barriers to interprofessional education. J Allied Health. 2013;42(4):202-213.

29. Austin AE. Faculty cultures, faculty values. New Direct Institut Res. 1990;1990(68):61-74.

30. Boateng W. Evaluating the Efficacy of Focus Group Discussion (FGD) in Qualitative Social Research. Int J Business Soc Sci. 2012;3(7):54-57.

31. Sarantakos S. Social Research. 4th ed. Basingstoke: Palgrave Macmillan; 2012.

32. Hoffman J, Redman-Bentley D. Comparison of faculty and student attitudes toward teamwork and collaboration in interprofessional education. J Interprof Care. 2012;26(1):66-68.

33. Bennett PN, Gum L, Lindeman I, et al. Faculty perceptions of interprofessional education. Nurse Educ Today. 2011;31(6):571-576.

34. Barnsteiner JH, Disch JM, Hall L, Mayer D, Moore SM. Promoting interprofessional education. Nurs Outlook. 2007;55(3):144-150.

35. Oandasan I, Reeves S. Key elements for interprofessional education. Part 1: the learner, the educator and the learning context. $J$ Interprof Care. 2005;19(Suppl 1):21-38.

36. Barker KK, Bosco C, Oandasan IF. Factors in implementing interprofessional education and collaborative practice initiatives: findings from key informant interviews. J Interprof Care. 2005;19(Suppl 1):166-176. 
37. Mueller D, Klingler R, Paterson M, Chapman C. Entry-level interprofessional education: perceptions of physical and occupational therapists currently practicing in Ontario. J Allied Health. 2008;37(4): 189-195.

38. Rafter M, Pesun I, Herren M, et al. A preliminary survey of interprofessional education. J Dental Educ. 2006;70(4):417-427.

39. Margalit R, Thompson S, Visovsky C, et al. From professional silos to interprofessional education: campuswide focus on quality of care. Qual Manag Health Care. 2009;18(3):165-173.

40. Curran VR, Deacon DR, Fleet L. Academic administrators' attitudes towards interprofessional education in Canadian schools of health professional education. J Interprof Care. 2005;19(Suppl 1):76-86.

41. Rafter ME, Pesun IJ, Herren M, et al. A preliminary survey of interprofessional education. J Dent Educ. 2006;70(4):417-427.

42. Baker C, Pulling C, McGraw R, Dagnone JD, Hopkins-Rosseel D, Medves J. Simulation in interprofessional education for patient-centred collaborative care. JAdv Nurs. 2008;64(4):372-379.

43. Curran VR, Sharpe D, Forristall J, Flynn K. Attitudes of health sciences students towards interprofessional teamwork and education. Learn Health Social Care. 2008;7(3):146-156.
44. Gilbert JH. Interprofessional learning and higher education structural barriers. J Interprof Care. 2005;19(Suppl 1):87-106.

45. Caldwell K, Atwal A. The problems of interprofessional healthcare practice in hospitals. Br J Nurs. 2003;12(20):1212-1218.

46. Brown J, Lewis L, Ellis K, Stewart M, Freeman TR, Kasperski MJ. Conflict on interprofessional primary health care teams--can it be resolved? J Interprof Care. 2011;25(1):4-10.

47. Alvarez $\mathrm{G}$, Coiera E. Interdisciplinary communication: an uncharted source of medical error? J Crit Care. 2006;21(3):236-242.

48. Goldsberry JW. Advanced practice nurses leading the way: Interprofessional collaboration. Nurse Educ Today. 2018;65:1-3.

49. Green BN, Johnson CD. Interprofessional collaboration in research, education, and clinical practice: working together for a better future. J Chiropr Educ. 2015;29(1):1-10.

50. Rudland JR, Mires GJ. Characteristics of doctors and nurses as perceived by students entering medical school: implications for shared teaching. Med Educ. 2005;39(5):448-455.

51. Dechairo-Marino AE, Jordan-Marsh M, Traiger G, Saulo M. Nurse/ physician collaboration: action research and the lessons learned. JNurs Adm. 2001;31(5):223-232.
Journal of Multidisciplinary Healthcare

\section{Publish your work in this journal}

The Journal of Multidisciplinary Healthcare is an international, peerreviewed open-access journal that aims to represent and publish research in healthcare areas delivered by practitioners of different disciplines. This includes studies and reviews conducted by multidisciplinary teams as well as research which evaluates the results or conduct of such teams or health

\section{Dovepress}

care processes in general. The journal covers a very wide range of areas and welcomes submissions from practitioners at all levels, from all over the world. The manuscript management system is completely online and includes a very quick and fair peer-review system. Visit http://www.dovepress.com/ testimonials.php to read real quotes from published authors. 